\title{
A Natural Reservoir and Transmission Vector of Grapevine Vein Clearing Virus
}

Sylvia M. Petersen, Cory Keith, Kaylie Austin, Susanne Howard, Li Su, and Wenping Qiu ${ }^{\dagger}$ Center for Grapevine Biotechnology, William H. Darr College of Agriculture, Missouri State University, Mountain Grove, MO 65711

\begin{abstract}
Grapevine vein clearing virus (GVCV) is associated with a vein-clearing and vine-decline disease. In this study, we surveyed wild Ampelopsis cordata from the Vitaceae family and found that $31 \%$ (35 of 113 ) of native $A$. cordata plants are infected with GVCV. The full-length genome sequence of one GVCV isolate from A. cordata shared $99.8 \%$ identical nucleotides with an isolate from a nearby cultivated 'Chardonel' grapevine, suggesting the occurrence of an insect vector. To identify a vector, we collected Aphis illinoisensis (common name: grape aphids) from wild A. cordata plants and detected GVCV in the aphid populations. We

found that A. illinoisensis is capable of transmitting GVCV from infected $A$. cordata to Chardonel grapevines in the greenhouse. Upon transmission, GVCV caused severe symptoms on the infected Chardonel 45 days post transmission. We conclude that wild GVCV isolates from $A$. cordata are capable of inducing a severe disease on cultivated grapevines once they spread from native $A$. cordata to vineyards via grape aphids. The discovery of a natural reservoir and an insect vector of GVCV provides timely knowledge for disease management in vineyards and critical clues on viral evolution and epidemiology.
\end{abstract}

A vein-clearing and vine-decline disease was first reported in a vineyard in 2007 (Qiu et al. 2007). The disease has caused the removal of five vineyards between 1 and 4 ha in Missouri and Arkansas, U.S.A., and its incidence has increased since then. Grapevine vein clearing virus (GVCV) has been found in a range of grape cultivars in five states in the Midwest region of the United States. The most susceptible grapevines show symptoms of translucent foliar vein clearing, edge rolling of leaves, deformed berries, dieback of cordons, vine stunting, and death of some vines (Qiu and Schoelz 2017). The disease is closely associated with GVCV, first discovered in a grape cultivar 'Chardonel' in Missouri in 2011 (Zhang et al. 2011).

GVCV belongs to the genus Badnavirus in the family Caulimoviridae (Zhang et al. 2011). The GVCV-CHA reference genome (GenBank accession no. NC015784) contains a double-stranded, circular DNA molecule of 7,753 bp. Three open reading frames (ORFs) are predicted on the plus-strand of the genome whose functions have not yet been fully characterized, except for the analogous annotation on the basis of functional motifs (Zhang et al. 2015). Nucleotide diversity within a GVCV population is in a range of 0.15 to $2.00 \%$ (Howard and Qiu 2017), and GVCV populations show diverse genetic variations among Vitis spp. at different geographic locations (Beach et al. 2017; Guo et al. 2014).

Two GVCV isolates, GVCV-VRU1 and GVCV-VRU2, were found in wild Vitis rupestris vines native to the Midwest region (Beach et al. 2017). GVCV-infected $V$. rupestris vines showed vein clearing and vein necrosis symptoms in their natural habitat and under greenhouse conditions. The genomes of GVCV-VRU1 (GenBank accession no. KJ725346) and GVCV-VRU2 (GenBank

${ }^{\dagger}$ Corresponding author: W. Qiu; E-mail: WenpingQiu@missouristate.edu

Funding: The authors extend thanks to the Missouri Grape and Wine Board for continuous support of their research programs.

GenBank accession numbers GVCV-AMP1, KX610316; GVCV-AMP2, KX610317; GVCV-AMP3, MH319694; GVCV-CHA2, MH319693; and ORF II sequences of 31 GVCV variants, KY849670 to KY849700.

*The $\boldsymbol{e}$-Xtra logo stands for "electronic extra" and indicates that one supplementary figure and two supplementary tables are published online.

Accepted for publication 8 August 2018.

This article is in the public domain and not copyrightable. It may be freely reprinted with customary crediting of the source. The American Phytopathological Society, 2018. accession no. KT907478) consist of 7,755 and 7,725 bp long DNA molecules, respectively. A 9-bp insert was found in the ORF II of GVCV-VRU1. The nucleotide sequence of ORF II is the most variable among sequenced GVCV genomes. Thus, the identity of the ORF II region was proposed as a criterion to differentiate GVCV variants with a critical value of $90 \%$ similarity (Beach et al. 2017). So far, only these two GVCV isolates were found out of 49 wild $V$. rupestris grapevines surveyed.

Ampelopsis cordata (common name: heartleaf peppervine) in the Vitaceae family shares habitats with native grapevines (Vitis spp.). A. cordata is indigenous to 20 states, from Nebraska to Texas, with highest density in Missouri, Arkansas, and Louisiana, and becoming sparse in the East Coast. These wild vines grow along riverbanks, fence rows, tree lines, and edges of commercial vineyards. No study has been reported on the status of viruses in A. cordata. Aphids, in particular Aphis illinoisensis (common name: grape aphids), infest A. cordata and wild Vitis spp., and they also colonize cultivated grapevines (Mifsud and Perez Hidalgo 2011).

Aphids transmit plant viruses in eight families including the family Caulimoviridae (Ng and Falk 2006; Ng and Perry 2004; Whitfield et al. 2015). Cauliflower mosaic virus (CaMV), the type member of the genus Caulimovirus, is transmitted by aphids in a semipersistent manner (Markham et al. 1987; Palacios et al. 2002). CaMV viral particles are acquired preferentially from phloem by aphids Brevicoryne brassicae L. and Myzus persicae (Palacios et al. 2002). Gooseberry vein banding associated virus $(\mathrm{GVBaV})$ is transmitted by Aphis grossulariae, Nasonovia ribisnigri, and Hyperomyzus spp. in a semipersistent manner (Adams and Posnette 1987). Rubus yellow net virus (RYNV), another badnavirus, is transmitted by the large raspberry aphid, Amphorophora idaei, in Europe and by A. agathonica in North America (Jones et al. 2002). It is notable that GVBaV and RYNV are most closely related to GVCV on the phylogenetic tree of badnaviruses (Bhat et al. 2016). The presence of grape aphids and a mild vein-clearing symptom on $A$. cordata prompted us to investigate GVCV infection in this wild plant species. We reasoned that grape aphids might be a candidate insect vector of GVCV.

In this study, we investigated (i) the presence of GVCV in A. cordata in Midwest flora and (ii) the role of the grape aphid in GVCV transmission. Finding a natural reservoir and a vector of GVCV is crucial for effective management of GVCV-associated disease and for understanding the origin and epidemiology of GVCV.

\section{Materials and Methods}

Collection of Ampelopsis and Vitis samples. Two mildly symptomatic A. cordata plants were collected, AMP1 from Linn Creek, MO, in the summer of 2015 and AMP2 from Springfield, MO, in 
the summer of 2014, $130 \mathrm{~km}$ apart. A Chardonel with severe GVCVassociated symptoms in a vineyard (CHA2) and a mildly symptomatic $A$. cordata (AMP3) climbing the fence surrounding that vineyard were collected from Coffman, MO, in the summer of 2016. Later, in a survey of GVCV in wild Vitaceae species, leaf samples were collected from native vines regardless of presence or absence of symptoms. Identification numbers, locations, GPS coordinates, and collection dates are compiled in Supplementary Table 1. A total of 113 A. cordata and 49 Vitis spp. samples were collected from seven regions across three states at a maximum distance of approximately $900 \mathrm{~km}$ between samples.

Extraction of DNA, polymerase chain reaction (PCR) assay of GVCV, and phylogenetic analysis. DNA was extracted by grinding leaf tissue in the presence of liquid nitrogen and using the DNeasy Plant Mini Kit (Qiagen). A PCR assay was implemented to conduct the survey of GVCV in collected samples. Two sets of primers, 1101F/1935R and 4363F/4804R (Supplementary Table 2) that were designed from the GVCV-CHA reference genome, yielded DNA fragments of 835 and $442 \mathrm{bp}$, respectively. Sequence variation among isolates necessitated two primer sets to reduce the chance of false negatives. Presence of one or both bands (835 and $442 \mathrm{bp}$ ) was accepted as a positive infection of GVCV. The third set of primers (16SF, 5'-TGCTTAACACATGCAAGTCGGA-3'; and 16SR, 5'-AGCCGTTTCCAGCTGTTGTTC-3') for amplifying a 105-bp DNA of grapevine 16S rRNA gene was included to verify the DNA quality and exclude the possibility of false negative results.

A set of primers, $963 \mathrm{~F}$ and $1634 \mathrm{R}$, was designed by finding conserved sequences flanking ORF II in all seven sequenced full-length GVCV genomes. The DNA fragments covering the entire ORF II region were amplified from GVCV-positive samples and were sequenced from both directions for the phylogenetic analysis. Thus, a PCR assay using the 963F/1634 primer set can be used as a diagnostic assay for infection by GVCV.

A phylogenetic tree was constructed with 48 sequenced ORF II regions by the maximum likelihood method with 1,000 bootstrap replicates using the Tamura-Nei model in the MEGA 7 software package (Felsenstein 1985; Kumar et al. 2016; Tamura and Nei 1993).

Assembly of GVCV genomes. The reference genome, GVCVCHA, was used to design primers for determining the whole genome sequence of the GVCV isolates AMP1, AMP2, AMP3, and CHA2. The reference genome sequence of 7,753 bp was divided into three overlapping fragments. A single band of each of the three fragments amplified by PCR was purified using the Qiagen MinElute Gel Extraction kit. Each of the three viral DNA fragments was inserted into a vector plasmid pCR8/GW/TOPO TA Cloning Kit (Invitrogen). Standard protocols of transformation and plasmid DNA purification were followed, with three distinct colonies used for verification of each fragment. The plasmid DNA samples were sequenced at Nevada Genomics Center, University of Nevada (Reno, NV). CodonCode Aligner was used to assemble the sequences with a cutoff Phred score of 20.

RNAseq and assembly of GVCV-AMP1 consensus genome. Total RNA from plant sample AMP1 was purified using a Norgen Plant/Fungi Total RNA Purification Kit (Thorold, ON, Canada). Total RNA was sent to Admera Health (South Plainfield, NJ) for Illumina sequencing. The library was prepared with the NEBNext Multiplex Small RNA Library Prep Set for Illumina (Set 1) with size selection. Adapters were removed using Cutadapt version 1.9.1 (Martin 2011), and reads were quality filtered using the NGS QC version 2.3.3 toolkit (Patel and Jain 2012). The NCBI BLAST algorithm was used to align reads of all lengths against a GI-mediated GenBank database of virus and viroid nucleotide sequences. Accessions that had more than 100 matched reads were further analyzed. The complete set of reads was aligned to the respective plant viral genome sequence alignments using Burrows-Wheeler Aligner (BWA version 0.7.12) (Li and Durbin 2009). Read alignment distribution was visualized using Integrated Genomics Viewer version 1.7 (Robinson et al. 2011). Single nucleotide polymorphisms (SNPs) were called using GATK UnifiedGenotyper version 4.0.7.0 with standard parameters (McKenna et al. 2010). Using the standalone version of NCBI BLAST version 2.6.0, all reads were aligned to a virus/ viroid database.

Collection of aphids and detection of GVCV. Grape aphids (A. illinoisensis) were collected from A. cordata vines in their native habitats. Aphid specimens from individual A. cordata vines were placed into separate bags and marked with the same identification number as the leaf sample from that vine. Specimens (voucher number E2017-4109-1) were identified at the Florida Department of Agriculture and Consumer Services. Aphids were preserved in $70 \%$ ethanol at $-20^{\circ} \mathrm{C}$. DNA was extracted from 10 to 20 aphids of each population with an Insect DNA Kit E.Z.N.A (Omega Bio-tek, Norcross, GA). A set of primers was designed to amplify a DNA fragment specific to an aphid elongation factor $(\mathrm{EF})$ gene to ensure quality DNA from aphid samples. The EF forward primer (5'-GG CTCTCCGTCTCCCACTCC-3) and EF reverse primer (5'-TGGTG ATGTTGGCAGGTGCG-3') were used in a diagnostic PCR along with GVCV-specific primers, 5044F and 5387R for detection of GVCV in aphids. In addition, the ORF II fragments of GVCV were amplified from aphids and sequenced for confirming identity of GVCV and for comparative analysis from their colonized plants using the protocol described in the previous section.

Aphid transmission assay. A single viviparous aphid was isolated from a GVCV-free A. cordata and transferred onto a virusfree Chardonel grape leaf inside a Petri dish. After the single aphid reproduced, the nymphs were placed onto a virus-free Chardonel grapevine in a BugDorm tent in the greenhouse. Aphid colonies were maintained on the Chardonel vines in an insect-proof greenhouse.

Colonies of A. illinoisensis were brushed from the leaves and tendrils and placed onto a paper towel in a Petri dish for $1 \mathrm{~h}$. They were then placed onto a detached GVCV-infected leaf. They were allowed to feed on the leaf for acquisition access periods (AAPs) of 5, 20, 40, and $60 \mathrm{~min}$. At the end of each AAP, 10 aphids were transferred to two GVCV-free Vidal blanc vines. Aphids were given a 24-h inoculation access period (IAP). The aphid-infested Vidal blanc vines were sprayed with insecticide (Safer Insect Killing Soap) after the 24-h IAP.

A group of 30 aphids were placed onto a GVCV-AMP1 infected A. cordata vine in an isolation tent for a 5-day AAP. Three virusfree Chardonel vines were moved into the tent, and 10 aphids were transferred to each Chardonel vine and allowed to feed on the vine for $48 \mathrm{~h}$. Aphids were treated with insecticide after the 48-h IAP. DNA was extracted from leaf tissues of the three recipient Chardonel vines at 60 days postinoculation and was subjected to PCR for detection of GVCV and analysis of ORF II sequences.

\section{Results}

GVCV was discovered in wild $A$. cordata. While surveying for GVCV in wild grapevines (Vitis spp.) in their native habitats, we observed mild vein-clearing, chlorotic spots, or mottle on leaves of some wild A. cordata vines. The symptomatic vine AMP1 was found at Linn Creek, MO, and AMP2 at Close Memorial Park in Springfield, MO. The plants were then propagated from green cuttings. They exhibited similar mild to moderate vein-clearing symptoms in the greenhouse. These symptoms are distinct from the severe, translucent, vein-clearing symptoms observed on GVCV-infected cultivated grapevines (Qiu and Schoelz 2017; Zhang et al. 2011).

A PCR assay for amplifying a GVCV-specific 835-bp fragment indicated that GVCV was present in both AMP1 and AMP2 samples, the first time GVCV has been found in a plant species belonging to a genus other than Vitis. We then determined the entire genome sequence of GVCV-AMP1 and GVCV-AMP2. The GVCV-AMP1 genome consists of 7,749 bp (GenBank accession no. KX610316), and the GVCV-AMP2 genome is 7,765 bp in length (GenBank accession no. KX610317). Three ORFs are predicted on the plus-strand of both genomes. The ORF II region of GVCV-AMP1 and GVCVAMP2 has a 9-nt insert and shares 83.2 and $88 \%$ identical nucleotides, respectively, with that of the reference GVCV-CHA genome. Therefore, GVCV-AMP1 and GVCV-AMP2 are new variants according to a proposed delineation (Beach et al. 2017). 

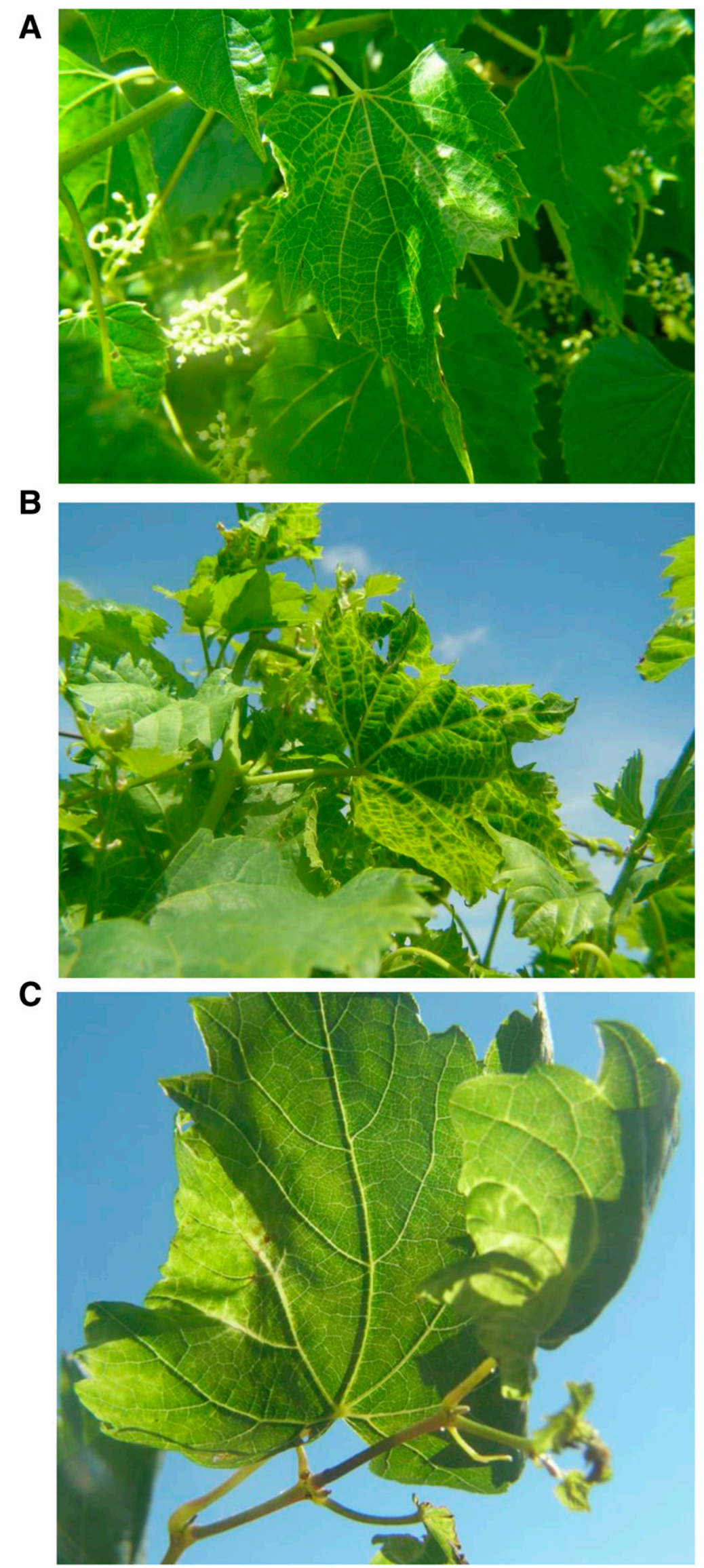

Fig. 1. Comparison of mild vein-clearing symptom on Ampelopsis cordata and severe symptoms on grape cultivar 'Chardonel' by the same grapevine vein clearing virus (GVCV) variant. A, Symptoms of GVCV-AMP3 infection on an A. cordata vine in its native habitat; B, deformed leaves and pronounced vein clearing on an adjacent GVCV-CHA2 infected Chardonel vine (the genomes of GVCV-AMP3 and GVCV-CHA2 share $99.8 \%$ identical nucleotide sequences); and C, induction of leaf-deformation symptom by GVCV-AMP1 on grape cultivar Chardonel 60 days after GVCV-AMP1 was transmitted from a mildly symptomatic $A$. cordata vine by grape aphids. 
To inquire into single-nucleotide sequence variations of the GVCV-AMP1 genome at quasispecies levels, small RNA sequences from the AMP1 leaf tissue sample were determined, and $99.6 \%$ coverage of the GVCV-AMP1 genome was obtained with 34 ambiguous nucleotides. A nearly full-length GVCV-AMP1 sequence was assembled from a consensus sequence in which eight SNPs were found in comparison with the GVCV-AMP1 genome obtained by Sanger sequencing. These SNPs, which are silent, are in the ORF III region.

The same GVCV variant was found in wild $A$. cordata and cultivated Chardonel. In one survey of GVCV in wild A. cordata, we observed a mildly symptomatic $A$. cordata along the fence of a vineyard of Chardonel grapevines (Fig. 1A) and a severely symptomatic Chardonel vine that grew within six meters (Fig. 1B). We collected leaf samples from the two plants, referred to as AMP3 and CHA2, and subjected them to PCR assay for GVCV. The virus was detected in both samples. The whole genome of GVCV-AMP3 and GVCV-CHA2 was then sequenced and shown to be 7,742 bp in size and $99.8 \%$ identical at the nucleotide level. These genomes share 93.5 and 93.3\% identical nucleotides with GVCV-AMP1 and GVCV-AMP2, respectively. Thus GVCV-AMP3 and GVCV-CHA2 are considered as one GVCV variant. However, the GVCV-CHA2 infected Chardonel vine showed severe symptoms including pronounced vein clearing, deformed leaves, and short internodes (Fig. 1B), in comparison to the mild vein clearing on $A$. cordata (Fig. 1A).

GVCV is widely distributed in wild $A$. cordata. To investigate the prevalence of GVCV among $A$. cordata in native habitats, we collected leaf samples of $A$. cordata plants from seven regions in accord with American Viticulture Areas (AVAs). Five AVAs lie within the borders of the Ozark Mountain AVA (III), which spans central to southern Missouri, northern Arkansas, and eastern Oklahoma. Three of the AVAs, Herman, Augusta, and Altus (I, II, and V) are in regions of historical importance to winemaking (Supplementary Fig. 1).

A total of 113 samples of $A$. cordata were collected from the seven regions, and GVCV was detected in 35 samples ( $31 \%$ infection rate). GVCV was found in 11 out of 14 locations, a prevalence rate of $79 \%$, in the three states (Arkansas, Missouri, and Oklahoma); 10 locations have at least a $25 \%$ infection rate (Table 1). In Springfield, MO, where three commercial vineyards exist within a $50-\mathrm{km}$ radius, GVCV was found in 33\% (6 of 18) of A. cordata, whereas no wild Vitis spp. (0\%, 0 of 14) were infected in this area.

To examine genetic relationships among GVCV isolates, DNA fragments covering the ORF II region (384 or $393 \mathrm{nt}$ ) from the GVCV-infected samples were sequenced. The ORF II sequences of nine GVCV isolates that were determined previously were also included in this analysis (Beach et al. 2017; Zhang et al. 2011). The

Table 1. Percentage of grapevine vein clearing virus (GVCV) infection in native Ampelopsis cordata vines at 14 locations in seven regions

\begin{tabular}{lccc}
\hline $\begin{array}{l}\text { Location (region, town, } \\
\text { state) }\end{array}$ & $\begin{array}{c}\text { Number of } \\
\text { samples }\end{array}$ & $\begin{array}{c}\text { GVCV }^{\mathbf{a}} \\
\text { positive }\end{array}$ & Percentage \\
\hline I, Hermann, MO & 12 & 3 & $25 \%$ \\
II, Augusta, MO & 3 & 1 & $33 \%$ \\
III, Coffman, MO & 12 & 5 & $42 \%$ \\
III, Mountain Grove, MO & 2 & 0 & $0 \%$ \\
III, Springfield, MO & 18 & 6 & $33 \%$ \\
III, Halltown, MO & 12 & 4 & $33 \%$ \\
III, Linn Creek, MO & 1 & 1 & $100 \%$ \\
III, Eureka Springs, AR & 9 & 4 & $44 \%$ \\
IV, London, AR & 2 & 0 & $0 \%$ \\
IV, Ponca, AR & 8 & 2 & $25 \%$ \\
IV, Hindsville, AR & 9 & 0 & $0 \%$ \\
V, Altus, AR & 15 & 2 & $13 \%$ \\
VI, Little Rock, AR & 7 & 5 & $71 \%$ \\
VII, Hinton, OK & 3 & 2 & $66 \%$ \\
Total & 113 & 35 & $31 \%$ \\
\hline
\end{tabular}

a A sample was determined to be positive if both GVCV-specific 835- and 442-bp fragments or a single fragment of 835 or 442 bp was amplified by polymerase chain reaction. Presence of GVCV was verified by sequencing the ORF II region of all GVCV-positive samples.
ORF II sequences of $33 \mathrm{GVCV}$ isolates in A. cordata and 15 in Vitis plants from seven designated regions were used to construct a phylogenetic tree (Fig. 2). Three defined clades with more than three variants were identified. GVCV variants from both A. cordata and Vitis plants were found in each clade. For instance, a total of five GVCV variants from $A$. cordata and three GVCV variants from Vitis plants within region III clustered together in clade II. This analysis indicated that GVCV variants spread across plant species within a designated geographical location.

GVCV was detected in grape aphids. While collecting leaf samples from native $A$. cordata, we found grape aphid populations on some plants. A total of 10 aphid colonies were collected from A. cordata and Vitis spp. GVCV was detected in four out of 10 aphid colonies (Fig. 3A). We sequenced the ORF II of GVCV variants from two aphid colonies. In both cases, the ORF II sequences of GVCV from aphids and the colonized A. cordata vines were $100 \%$ identical. In one case, the GVCV variant from aphids and $A$. cordata contained the 9-nt insert in ORF II (393 nt). In the other case, the GVCV variant from aphids and A. cordata did not contain the 9-nt insert in ORF II (384 nt). These results suggested that grape aphids can acquire GVCV from the host $A$. cordata.

GVCV is transmitted from $A$. cordata to Chardonel grapevine by the grape aphid. To test if the grape aphid can transmit GVCV, we established a colony of grape aphids from a single viviparous female aphid. In a preliminary experiment to evaluate the capacity of aphids to acquire GVCV, we allowed aphids to feed on GVCVinfected grapevine leaves for 5, 20, 40, and $60 \mathrm{~min}$. We detected GVCV only in a group of 10 aphids after they fed for $40 \mathrm{~min}$. To test directly for transmission of GVCV, we transferred nonviruliferous aphids onto $A$. cordata infected with GVCV-AMP1. The aphids were allowed to feed on GVCV-AMP1 infected A. cordata for $48 \mathrm{~h}$ and then were transferred to three Chardonel vines that tested negative for GVCV. Two out of three Chardonel vines developed symptoms typical of GVCV at 45 days after the aphid transmission (Fig. 1C). The symptoms that developed on the Chardonel vines were pronounced translucent vein clearing and deformation of young leaves (Fig. 1C), in contrast to mild vein clearing observed on wild A. cordata (Fig. 1A). GVCV was detected in all three Chardonel vines at 60 days postinoculation (Fig. 3B). The ORF II sequences of the GVCV isolates from the three recipient Chardonel vines were $100 \%$ identical to each other and $99.5 \%$ identical to GVCVAMP1. We concluded that A. illinoisensis can transmit GVCV from A. cordata to Chardonel vines and that GVCV-AMP1 induces a severe disease on Chardonel vines.

\section{Discussion}

In this study, we asked two questions: does GVCV infect wild species other than Vitis species, and how does GVCV spread? We found that GVCV infects $31 \%$ of wild $A$. cordata vines in their native habitats. We detected GVCV in grape aphids (A. illinoisensis) that were collected from GVCV-infected wild A. cordata vines. We provided evidence that grape aphids are able to transmit a GVCV variant from A. cordata to Chardonel. We found that wild GVCV-AMP1 variant induces severe symptoms on grape cultivar Chardonel 45 days after it is vectored from $A$. cordata.

Badnaviruses are regarded as a highly diverse and heterogeneous group of viruses (Borah et al. 2013; Geering et al. 2000; Karuppaiah et al. 2013; Muller et al. 2011; Sharma et al. 2015). They infect a wide range of important crops and pose a serious problem to the exchange and healthy growth of vegetatively propagated plants. It is difficult to manage badnavirus-associated diseases because sources of most badnaviruses remain unknown (Bhat et al. 2016). GVCV is considered a recently emerging badnavirus in cultivated grapevines (Zhang et al. 2011). Emergence of viruses in crops generally begins with migration of viral isolates from a wild reservoir to a cultivated plant (Fraile et al. 2017; Jones and Coutts 2015; Stobbe et al. 2012; Tugume et al. 2010, 2016; Vincent et al. 2014; Wren et al. 2006). In the interface of wild plants and cultivated crops, emerging viruses expand the host range across plant species of different genera and families owing to ecosystem alterations and viral evolution (Bhat 
et al. 2016; Roossinck and García-Arenal 2015). Expansion of viticultural areas in the Midwest brought cultivated Vitaceae species close to native Vitaceae species. This study documents that GVCV infects a plant species belonging to a genus other than Vitis. High prevalence of GVCV in widely distributed $A$. cordata plants and recent intensification of growing grapevines support a scenario in which GVCV is likely spreading to cultivated grapevines because of cross-species transmission.

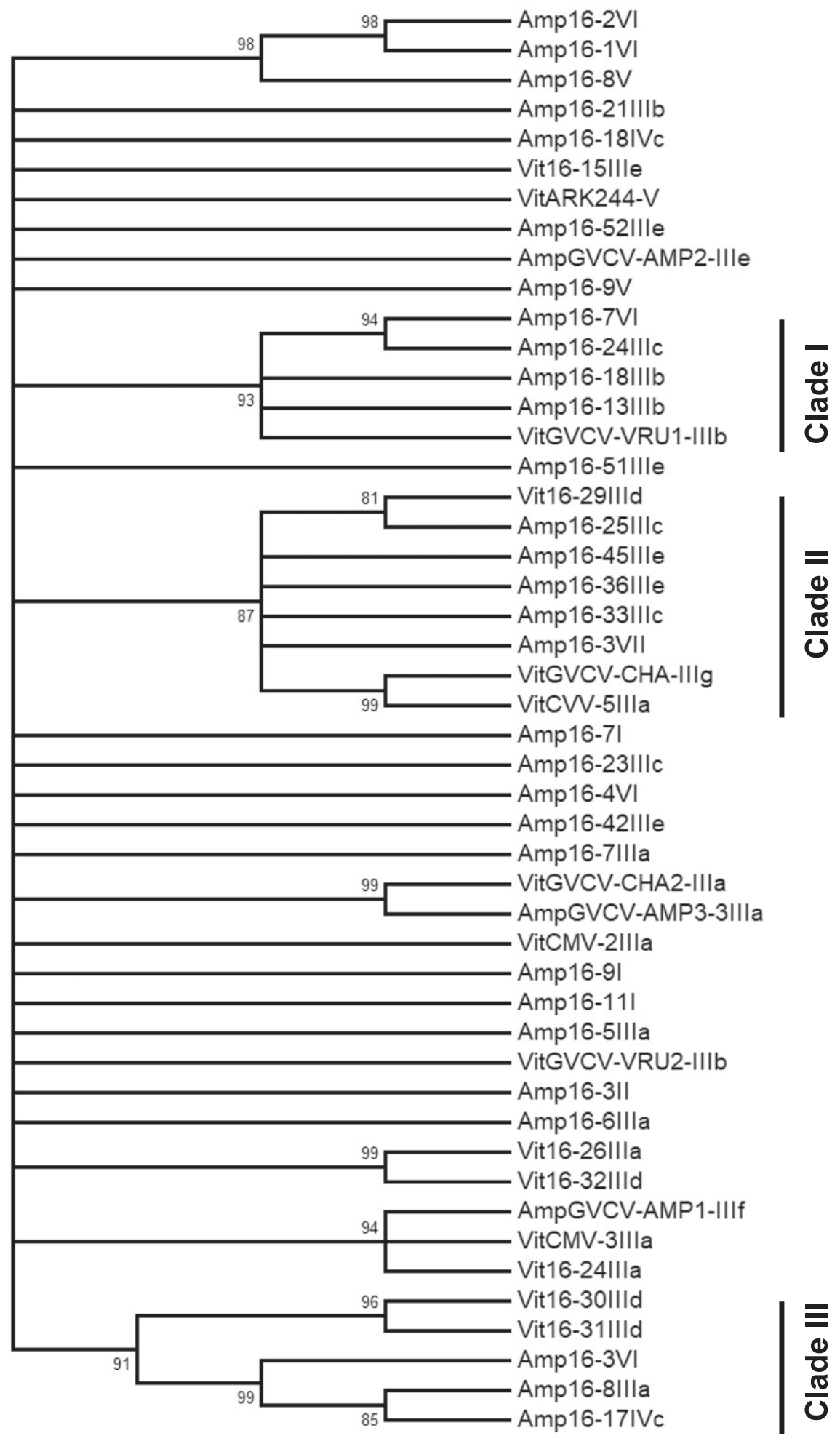

Fig. 2. Phylogenetic analysis of 48 grapevine vein clearing virus (GVCV) isolates based on the ORF II sequences. The evolutionary history was inferred by using the maximum likelihood method with 1,000 bootstrap replicates in MEGA7. Branches corresponding to partitions reproduced in less than $70 \%$ bootstrap replicates are collapsed. The percentage of replicate trees in which the associated taxa clustered together in the bootstrap test (1,000 replicates) are shown next to the nodes. A total of 33 Ampelopsis and 15 Vitis isolates are included in this analysis. Nomenclature of sample ID Amp16-1Illa: Amp = Ampelopsis cordata; Vit $=$ Vitis species; $16=$ the year (2016) collected; $1=$ the series number of sample in that particular region; $I I I=$ the seven regions where samples were collected; and $a=$ town or location in that region. The seven geographical regions were designated largely based on American Viticultural Areas (AVAs). A list of the Roman numerals and the corresponding regions are as follows: I= Hermann, MO, AVA; $I I=$ Augusta, MO, AVA; III = Ozark Mountain and Ozark Highlands AVAs ( $a=$ Coffman, MO; $b=$ Eureka Springs, AR; $c=$ Halltown, MO; $d=$ Mountain Grove, MO; $e=S p r i n g f i e l d, M O ; f=$ Linn Creek, MO; and $\mathrm{g}=$ Rocheport, MO); IV = Arkansas Mountain AVA ( $\mathrm{a}=$ Hindsville, AR; $\mathrm{b}=$ London, AR; and $\mathrm{c}=$ Ponca, AR); V = Altus, AR, AVA; VI = Little Rock, AR; and VII = Hinton, OK 
$A_{M}$

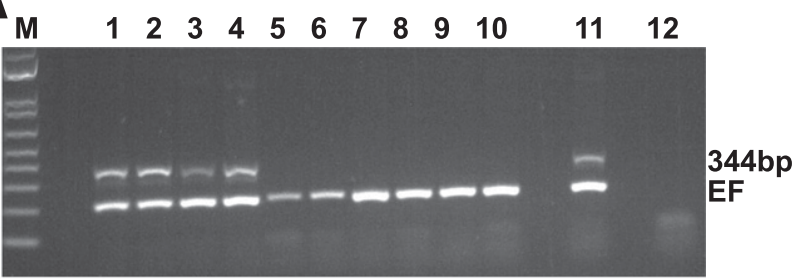

B

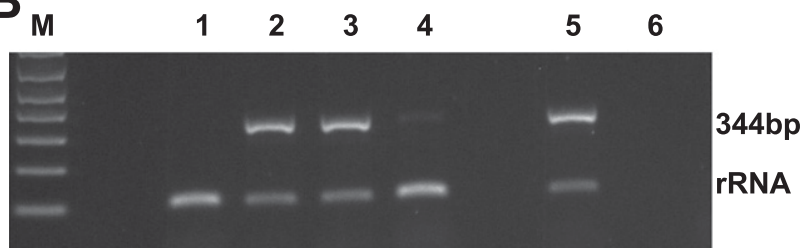

Fig. 3. Detection of grapevine vein clearing virus (GVCV) in wild grape aphid colonies and in 'Chardonel' vines after the transmission of GVCV-AMP1. A, Presence of GVCVspecific DNA fragment in the four aphid colonies. Lanes 1 to $10=10$ wild grape aphid colonies that were subjected to polymerase chain reaction (PCR) assay; lane $11=$ GVCV-positive sample; and lane 12 = negative control without DNA template. DNA fragment specific to aphid elongation factor (EF) was amplified from all aphid colonies to indicate the DNA quality. B, Presence of GVCV-specific DNA fragment in the three Chardonel vines after GVCV-AMP1 was transmitted by grape aphids. Lane 1 = virus-free Chardonel vine that was used for propagation of recipient Chardonel vines; lanes 2 to $4=$ three recipient Chardonel vines (leaves were sampled for PCR assay at 60 days post transmission); lane $5=$ GVCV-AMP1 infected $A$. cordata vine on which aphids were allowed to feed for 5 days before transmission; and lane $6=$ negative control. A set of GVCV-specific primers, 5044F and 5387R, was used in PCR to amplify a 344-bp DNA fragment in ORF III. A 106-bp DNA fragment was amplified by PCR using a pair of grapevine rRNAspecific primers, which was used as a reference gene for the presence of plant DNA.

The $31 \%$ incidence of GVCV in A. cordata and the infection of a wild $A$. cordata and a cultivated grapevine by the same GVCV variant suggest the presence of a pervasive transmission vector. Grape aphids (A. illinoisensis) are native to the North American continent and colonize wild A. cordata plants and thus were selected for this study. Subsequently, we detected GVCV in four wild grape aphid populations (Fig. 3). In two of the four colonies, GVCV was also detected in the host $A$. cordata plants. Significantly, the GVCV sequences recovered from the aphids matched the GVCV sequences in their A. cordata hosts. Transmission experiments provided direct evidence that grape aphids are capable of transmitting GVCV from $A$. cordata to grape cultivars (Fig. $1 \mathrm{C}$ and 3 ). Thus, it is clear that A. illinoisensis is a vector that transmits GVCV. Grape aphids in North America are heteroecious and alternate between Viburnum prunifolium and Vitaceae species (Baker 1917). Spring migrants typically fly up to $20 \mathrm{~km}$ from $V$. prunifolium to their new host. This appears to be consistent with the local epidemic pattern of GVCV in wild plants and in vineyards.

Native hosts to viral pathogens often exhibit no or mild symptoms owing to the close evolutionary relationship of a pathogen and a host (Jones 2009). This is clearly the case with GVCV infection in wild $A$. cordata plants (Fig. 1A). Once GVCV spreads from its native hosts to cultivated grapevines, it results in severe symptoms (Fig. 1B and C). Although proving the etiological role of GVCV in the disease requires construction of an infectious clone, the results provide convincing evidence that GVCV is a causative agent of this severe disease on cultivated grapevines.

In conclusion, wild $A$. cordata vines serve as a significant inoculum source, although they may not be the sole alternative host of GVCV. Thus, it is a good practice to remove wild A. cordata vines around vineyards. This will reduce alternative inoculum sources of GVCV and the number of hosts for grape aphids.

\section{Acknowledgments}

We are grateful to James Schoelz for critical review of the manuscript and Carley Petersen for editing the manuscript. We thank Susan Halbert and
Katherine Fairbanks in the Florida Department of Agriculture and Consumer Services for verifying the identity of the aphid.

\section{Literature Cited}

Adams, A. N., and Posnette, A. F. 1987. Gooseberry vein banding. Pages 129-130 in: Virus Diseases of Small Fruits. R. H. Converse, ed. USDA Agriculture Handbook No. 631. USDA, Washington, DC.

Baker, A. C. 1917. Life history of Macrosiphum illinoisensis, the grapevine aphis. J. Agric. Res. 11:85-90

Beach, S., Kovens, M., Hubbert, L., Honesty, S., Guo, Q., Pap, D., Dai, R. Kovacs, L., and Qiu, W. 2017. Genetic and phenotypic characterization of grapevine vein clearing virus from wild Vitis rupestris. Phytopathology 107: 138-144.

Bhat, A. I., Hohn, T., and Selvarajan, R. 2016. Badnaviruses: The current global scenario. Viruses 8:177.

Borah, B. K., Sharma, S., Kant, R., Johnson, A. M., Saigopal, D. V., and Dasgupta, I. 2013. Bacilliform DNA-containing plant viruses in the tropics: Commonalities within a genetically diverse group. Mol. Plant Pathol. 14: 759-771.

Felsenstein, J. 1985. Confidence limits on phylogenies: An approach using the bootstrap. Evolution 39:783-791.

Fraile, A., McLeish, M. J., Pagán, I., González-Jara, P., Piñero, D., and GarcíaArenal, F. 2017. Environmental heterogeneity and the evolution of plantvirus interactions: Viruses in wild pepper populations. Virus Res. 241: 68-76.

Geering, A., McMichael, L. A., Dietzgen, R. G., and Thomas, J. E. 2000. Genetic diversity among banana streak virus isolates from Australia. Phytopathology 90:921-927.

Guo, Q., Honesty, S., Xu, M. L., Zhang, Y., Schoelz, J. E., and Qiu, W. P. 2014 Genetic diversity, tissue and host specificity of grapevine vein clearing virus. Phytopathology 104:539-547.

Howard, S., and Qiu, W. 2017. Viral small RNAs reveal the genomic variations of three grapevine vein clearing virus quasispecies populations. Virus Res. 229: 24-27.

Jones, A. T., McGavin, W. J., Geering, A. D. W., and Lockhart, B. E. L. 2002 Identification of Rubus yellow net virus as a distinct badnavirus and its detection by PCR in Rubus species and in aphids. Ann. Appl. Biol. 141:1-10.

Jones, R. A. C. 2009. Plant virus emergence and evolution: Origins, new encounter scenarios, factors driving emergence, effects of changing world conditions, and prospects for control. Virus Res. 141:113-130.

Jones, R. A. C., and Coutts, B. A. 2015. Spread of introduced viruses to new plants in natural ecosystems and the threat this poses to plant biodiversity. Mol. Plant Pathol. 16:541-545.

Karuppaiah, R., Viswanathan, R., and Kumar, V. G. 2013. Genetic diversity of sugarcane bacilliform virus isolates infecting Saccharum spp. in India. Virus Genes 46:505-516.

Kumar, S., Stecher, G., and Tamura, K. 2016. MEGA7: Molecular Evolutionary Genetics Analysis version 7.0 for bigger datasets. Mol. Biol. Evol. 33: $1870-1874$

Li, H., and Durbin, R. 2009. Fast and accurate short read alignment with Burrows-Wheeler transform. Bioinformatics 25:1754-1760.

Markham, P. G., Pinner, M. S., Raccah, B., and Hull, R. 1987. The acquisition of a caulimovirus by different aphid species: Comparison with a potyvirus. Ann. Appl. Biol. 111:571-587

Martin, M., 2011. Cutadapt removes adapter sequences from high-throughput sequencing reads. EMBnet.journal 17:10-12.

McKenna, A., Hanna, M., Banks, E., Sivachenko, A., Cibulskis, K., Kernytsky, A., Garimella, K., Altshuler, D., Gabriel, S., Daly, M., and DePristo, M. A. 2010. The Genome Analysis Toolkit: A MapReduce framework for analyzing nextgeneration DNA sequencing data. Genome Res. 20:1297-1303.

Mifsud, D., and Perez Hidalgo, N. 2011. The grapevine aphid Aphis illinoisensis: A good example of recent invasion and rapid colonization by aphids. EPPO Bull. 41:183-184.

Muller, E., Dupuy, V., Blondin, L., Bauffe, F., Daugrois, J.-H., Nathalie, L., and Iskra-Caruana, M.-L. 2011. High molecular variability of sugarcane bacilliform viruses in Guadeloupe implying the existence of at least three new species. Virus Res. 160:414-419.

Ng, J. C. K., and Falk, B. W. 2006. Virus-vector interactions mediating nonpersistent and semipersistent transmission of plant viruses. Annu. Rev. Phytopathol. 44:183-212.

Ng, J. C. K., and Perry, K. L. 2004. Transmission of plant viruses by aphid vectors Mol. Plant Pathol. 5:505-511.

Palacios, I., Drucker, M., Blanc, S., Leite, S., Moreno, A., and Fereres, A. 2002 Cauliflower mosaic virus is preferentially acquired from the phloem by its aphid vectors. J. Gen. Virol. 83:3163-3171.

Patel, R. K., and Jain, M. 2012. NGS QC Toolkit: A toolkit for quality control of next generation sequencing data. PLoS One 7:e30619.

Qiu, W., and Schoelz, J. 2017. Grapevine vein clearing virus: Diagnostics, genome, genetic diversity, and management. Pages 315-330 in: Grapevine Viruses: Molecular Biology, Diagnostics and Management. B. Meng, G. P. Martelli, D. A. Golino, and M. Fuchs, eds. Springer International Publishing, Cham, Switzerland. 
Qiu, W. P., Avery, J. D., and Lunden, S. 2007. Characterization of a severe viruslike disease in Chardonnay grapevines in Missouri. Online publication. Plant Health Prog. 8.

Robinson, J. T., Thorvaldsdottir, H., Winckler, W., Guttman, M., Lander, E. S., Getz, G., and Mesirov, J. P. 2011. Integrative genomics viewer. Nat. Biotechnol. 29:24-26.

Roossinck, M. J., and García-Arenal, F. 2015. Ecosystem simplification, biodiversity loss and plant virus emergence. Curr. Opin. Virol. 10: 56-62.

Sharma, S. K., Vignesh Kumar, P., Geetanjali, A. S., Pun, K. B., and Baranwal, V. K. 2015. Subpopulation level variation of banana streak viruses in India and common evolution of banana and sugarcane badnaviruses. Virus Genes 50: $450-465$.

Stobbe, A. H., Melcher, U., Palmer, M. W., Roossinck, M. J., and Shen, G. 2012. Co-divergence and host-switching in the evolution of tobamoviruses. J. Gen. Virol. 93:408-418.

Tamura, K., and Nei, M. 1993. Estimation of the number of nucleotide substitutions in the control region of mitochondrial DNA in humans and chimpanzees. Mol. Biol. Evol. 10:512-526.

Tugume, A. K., Cuéllar, W. J., Mukasa, S. B., and Valkonen, J. P. T. 2010. Molecular genetic analysis of virus isolates from wild and cultivated plants demonstrates that East Africa is a hotspot for the evolution and diversification of sweet potato feathery mottle virus. Mol. Ecol. 19:31393156.

Tugume, A. K., Mukasa, S. B., and Valkonen, J. P. T. 2016. Mixed infections of four viruses, the incidence and phylogenetic relationships of sweet potato chlorotic fleck virus (Betaflexiviridae) isolates in wild species and sweetpotatoes in Uganda and evidence of distinct isolates in East Africa. PLoS One 11:e0167769.

Vincent, S. J., Coutts, B. A., and Jones, R. A. C. 2014. Effects of introduced and indigenous viruses on native plants: Exploring their disease causing potential at the agro-ecological interface. PLoS One 9:e91224.

Whitfield, A. E., Falk, B. W., and Rotenberg, D. 2015. Insect vector-mediated transmission of plant viruses. Virology 479-480:278-289.

Wren, J. D., Roossinck, M. J., Nelson, R. S., Scheets, K., Palmer, M. W., and Melcher, U. 2006. Plant virus biodiversity and ecology. PLoS Biol. 4:e80.

Zhang, Y., Angel, C. A., Valdes, S., Qiu, W., and Schoelz, J. E. 2015 Characterization of the promoter of grapevine vein clearing virus. J. Gen. Virol. 96:165-169.

Zhang, Y., Singh, K., Kaur, R., and Qiu, W. 2011. Association of a novel DNA virus with the grapevine vein-clearing and vine decline syndrome. Phytopathology 101:1081-1090. 